\title{
Anthropologie et migrations africaines en France : une généalogie des recherches
}

Anthropology and African Migrations in France: A Genealogy of Researches

Antropología y migraciones africanas en Francia: genealogía de las

investigaciones

Liliane Kuczynski et Élodie Razy

\section{(2) OpenEdition}

Journals

\section{Édition électronique}

URL : https://journals.openedition.org/remi/4988

DOI : $10.4000 /$ remi.4988

ISSN : $1777-5418$

Éditeur

Université de Poitiers

\section{Édition imprimée}

Date de publication : 1 décembre 2009

Pagination : 79-100

ISBN : 978-2-911627-53-8

ISSN : 0765-0752

Référence électronique

Liliane Kuczynski et Élodie Razy, «Anthropologie et migrations africaines en France : une généalogie des recherches », Revue européenne des migrations internationales [En ligne], vol. 25 - n³ | 2009, mis en ligne le 01 décembre 2012, consulté le 15 avril 2022. URL : http://journals.openedition.org/remi/4988 ; DOI : https://doi.org/10.4000/remi.4988 


\section{Anthropologie et migrations africaines en France : une généalogie des recherches}

\section{Liliane KUCZYNSKI* et Élodie RAZY**}

Longtemps la perception et le traitement de l'immigration en France ont rimé avec Maghreb. La présence en France de ressortissants des pays d'Afrique subsaharienne, plus tardive il est vrai, et moins importante numériquement que celle des populations d'Afrique du Nord est longtemps passée inaperçue. Par ailleurs, s'agissant de la constitution du champ scientifique, si les thématiques relatives aux migrations sont restées des années durant largement marginalisées voire dépréciées, des disciplines telles la géographie, la démographie et la sociologie s'en sont néanmoins saisies bien avant l'anthropologie. Sans doute la cécité particulière de cette dernière trouve-t-elle une de ses raisons dans la grande tradition africaniste française, longtemps dominée par l'école griaulienne et la « passion dogon » (Albers, 2006), qui a privilégié les enquêtes dans la brousse africaine et mis l'accent sur l'étude des rituels et des mythes. Il n'est pas indifférent que, comme l'a raconté Georges Balandier, Marcel Griaule ait cherché à le dissuader d'entreprendre un terrain en milieu urbain et que, ayant outrepassé cet interdit, le premier ait placé ses écrits sous l'égide de la sociologie plutôt que de l'ethnologie'. Si, depuis cette époque, les études sur les villes africaines se sont multipliées, c'est sur les terrains situés hors d'Afrique que cette réticence s'est déplacée et longtemps maintenue : bien des ethnologues travaillant sur les migrations africaines ont encore jusqu'à récemment éprouvé la résistance et l'incompréhension de leurs pairs africanistes à l'égard des recherches en France. Comment une approche anthropologique de ce phénomène doublement occulté s'est-elle peu à peu imposée ? Dans quelle mesure le contexte politique et idéologique français a-t-il marqué ces recherches de son emprise ? Plus que d'un tableau exhaustif, il s'agira, à travers

\footnotetext{
* Chercheuse au CNRS, Laboratoire d'anthropologie urbaine ; kuczynski@ivry.cnrs.fr

** Chargée de cours en Anthropologie, Université de Liège (Laboratoire d'anthropologie sociale et culturelle) et Laboratoire d'anthropologie urbaine ; elodie.razy@ulg.ac.be

1 « Ne travaille pas sur la ville. En ville il n'y a que des bribes d'Afrique », aurait dit Griaule. Ce désaccord entre Balandier et Griaule est évoqué par Laurent Amiotte-Suchet et Pierre Floux (2002).
} 
quelques exemples emblématiques, de montrer la genèse des thèmes et le modelage des différentes figures du migrant africain qui sont nées de ces travaux².

\section{LE TRAVAILLEUR DANS TOUS SES ÉTATS}

C'est à partir du milieu des années soixante, alors que leur présence en France commence à s'intensifier, que les migrants africains font leur apparition dans quelques rares études de sciences sociales ${ }^{3}$. Cependant des historiens nous rappellent que cette immigration est loin d'être récente : ainsi Marc Michel (2003), Éric Deroo et Antoine Champeaux (2006) étudient la « force noire » et l'histoire, depuis la seconde moitié du XIXe siècle, des tirailleurs sénégalais dont certains sont restés en France ; Philippe Dewitte (1985) retrace l'histoire des « mouvements nègres en France de 1919 à 1939 », thème également développé dans plusieurs publications depuis le milieu des années quatre-vingt ${ }^{4}$. Dans le registre littéraire, le roman de Claude McKay, Banjo, décrit avec une précision toute ethnographique, dès la fin des années vingt, l'existence des " navigateurs » noirs américains, antillais et africains dans le port de Marseille et le regard, entre mépris et connivence, porté sur eux par les autres habitants de ce quartier ${ }^{5}$. L'histoire de ces marins, dont la présence est attestée en France dès le milieu du XIXe siècle, a été reprise notamment par François Manchuelle (2004 : 249 et suivantes) et par Brigitte Bertoncello et Sylvie Bredeloup (1999).

Concernant les migrations de la période postcoloniale, c'est sur la figure du « travailleur immigré » que se sont d'abord focalisées les recherches, qui, pour la plupart, laissent de côté la présence ancienne en France d'étudiants et d'intellectuels originaires de divers pays d'Afrique ${ }^{6}$. À partir de 1961 paraissent dans la presse, dans des revues associatives, et notamment dans les Cahiers nord-africains ${ }^{7}$, des articles en nombre croissant, qui dévoilent la présence en France de ces « travailleurs », terme qui figure dans la quasi-tota-

2 Sans méconnaître les travaux de chercheurs notamment anglo-saxons sur la migration africaine en France (Ebin, Cordell, Sargent, etc.), le poids particulier du contexte français, tant politique que scientifique, explique que ne soit envisagée dans cet article que la production française sur ce thème.

3 De même que dans les représentations audiovisuelles. Cf. dans l'ouvrage de E. Mills-Affif, le chapitre consacré à la migration africaine (2004:139-178).

4 Cf. par exemple Black, Africains, Antillais, cultures noires en France (1983) et plus récemment, Le Paris noir (2001) et Black Paris. Kunst und Geschichte einer schwarzen Diaspora (2006).

5 Le roman est paru aux États-Unis en 1928. L'auteur fait partie du mouvement de la Renaissance de Harlem. Ce thème des dockers est aussi traité dans le roman de Sembene Ousmane Le docker noir (1956).

6 Mentionnons cependant la posture originale de Jean Rouch qui, dans ses films Chronique d'un été (1961) et Petit à petit (1971), met en scène des étudiants africains portant leur regard sur la société française ; le cinéaste inaugure ainsi ce qu'on nommera plus tard « ethnologie inverse ».

7 Publication initialement consacrée aux travailleurs maghrébins fondée en 1950 par le père blanc Jacques Ghys et qui deviendra, en 1965, la revue Hommes et migrations. Cf. notamment J.-P. Rosier et J. Leriche (1961) Africains noirs en France, n 86, 64 p. ; et le numéro spécial, Approche des problèmes de la migration noire en France (1965), n 104. 
lité des titres de ces publications. Celles-ci sont centrées sur deux préoccupations : d'une part celle des conditions de venue et d'existence en France de cette " main-d'œuvre » africaine et de son adaptabilité au monde urbain et industriel français ; d'autre part celle de la pathologie qui lui est propre (maladies tropicales éventuellement importées, mais aussi fragilité due au climat, à la méconnaissance du monde industriel, aux mauvaises conditions de logement, de même que pathologie mentale). Parmi ces parutions, paternalistes ou dénonciatrices, une place particulière doit être faite à l'étude bien documentée de Souleymane Diarra. Dans un premier article paru dans la revue Psychopathologie africaine (1966), puis développé dans le Bulletin de l'IFAN (1968) ${ }^{8}$, il propose, en géographe, une " vue d'ensemble des problèmes relatifs à l'implantation des travailleurs africains noirs en France » (1968: 885) ; il souligne la méconnaissance des pouvoirs publics français à leur égard jusqu'en $1963^{9}$; il définit avec une grande précision les lieux d'origine de ces jeunes hommes généralement analphabètes issus de zones rurales, retrace l'histoire de leur venue, leur localisation sur le territoire français, leurs conditions d'embauche, de travail - généralement sous-qualifié -, de paiement, leur logement misérable, leur organisation sociale communautaire, enfin les effets de la «formation (de ce) sous-prolétariat nouveau » (ibid. : 995) sur les pays de départ comme d'arrivée. Dans une recension parue dans les Annales en 1969, Pierre Souyri salue " l'étude très valable » de Diarra mais regrette « qu'il n'ait pas cherché à nous renseigner davantage sur la façon dont les émigrés noirs vivent l'expérience de leur séjour en France » $(1969,1: 176)$ : porte ouverte à une étude ethnologique de cette migration? Il faudra attendre quelques années pour la voir naître.

Plus généralement, et de façon de plus en plus marquée, c'est une approche en termes économiques plus ou moins empreinte de marxisme qui a dominé les études de cette époque sur l'immigration en France de même qu'une partie de celles consacrées aux migrations internes à l'Afrique. Paru en 1976, l'ouvrage collectif dirigé par Jean-Loup Amselle Les migrations africaines. Réseaux et processus migratoires considère les phénomènes migratoires comme «l'expression des symptômes caractérisant l'ensemble des sociétés dominées ». À l'auteur d'une recension qui lui reproche de ne pas avoir employé de concepts marxistes plus durs, tel celui d' « accumulation primitive » et de ne pas avoir consacré un chapitre à l'émigration vers la France, il répond : «Il m'a semblé (...) que la situation des migrants travaillant dans le secteur capitaliste en Afrique du Sud et celle des immigrés chez Renault était comparable. Là encore, je voulais échapper à tout géographisme dans l'analyse et mettre en lumière l'unité profonde du système impérialiste $»^{10}$.

Il faut rappeler le poids dans les années soixante-dix de la pensée marxiste sur les études d'anthropologie en général, et noter aussi la publication privilégiée de ces écrits aux Éditions Maspero. La célèbre collection « textes à l'appui » est placée « sous la responsabilité d'un collectif africaniste animé par Claude Meillassoux, Pierre-Philippe Rey, Emmanuel Terray ».

8 Remarquons que ces deux revues sont éditées à Dakar et non à Paris.

9 C'est à cette date que le gouvernement français signa avec le Sénégal, le Mali et la Mauritanie les premiers accords régulant l'immigration.

10 Recension par A. Bourgeot (1977) L’Homme, n XVII (2-3), pp. 117-123 et réponse en 1978, $n^{\circ}$ XVIII (1-2), pp. 183-184. 
Un autre exemple de cette influence est le livre de Michel Samuel, paru en 1978, dont le titre parle de lui-même : Le prolétariat africain noir en France. Il faut noter que ces études axées sur les conditions du travail en France s'inscrivent dans le sillage d'une thématique initiée par les Africains eux-mêmes : par exemple les luttes menées par Sally Ndongo et ses écrits, et Le livre des travailleurs africains en France, paru en 1972 émanant de l'Union Générale des Travailleurs Sénégalais en France. Michel Samuel (qui se définit comme "sociologue » mais a soutenu sa thèse avec Louis-Vincent Thomas) traite des Soninké de la région du fleuve Sénégal, première région d'émigration, de la gestion de l'émigration dans les familles, de l'exploitation du travailleur immigré en France, des foyers, de l'organisation sociale des regroupements villageois à l'intérieur des foyers (le village dans les foyers), de la religion, des caisses de village, etc. Son analyse repose sur les témoignages des migrants, recueillis à Paris et à Dakar et n'est pas centrée sur des observations directes. Ce livre reste très informatif, fourmille de détails, mais est très marqué par l'approche de cette époque.

Le traitement du travailleur africain et de son exploitation n'a pas été le seul thème développé dans les années soixante, soixante-dix : des géographes, des démographes, des sociologues se sont également intéressés aux flux monétaires et à leurs effets en Afrique ; ces études ont aussi envisagé d'autres groupes que les Soninké, en particulier les Toucouleurs (Kane et Lericollais, 1975 ; Dubresson, 1975). Nous-mêmes, anthropologues, nous sommes nourris de ces travaux dont les thèmes sont repris aujourd'hui.

Mais pour notre propos qui vise à cerner la place de l'anthropologie dans les travaux sur la migration d'Afrique subsaharienne, le tournant est constitué par les travaux de Jacques Barou, tout à fait concomitants de ceux de Samuel puisque son livre, Travailleurs africains en France. Rôle des cultures d'origine publié aux PUG/Publications orientalistes de France, paraît également en 1978 ; un tournant parce que Barou est le premier à franchir le pas de l'étude des migrations en s'intéressant aux mouvements externes au continent africain avec des outils nouveaux. Il se dégage quelque peu de la problématique du prolétariat et des foyers pour considérer les Africains dans leur culture d'origine. Barou est le premier à affirmer que le seul moyen d'appréhender ces cultures et la « complexité du vécu », c'est « une démarche de type ethnologique » (ibid. : 10) ${ }^{11}$. Sa position de recherche dans deux groupes différents (haoussa et soninké, à Lyon et à Paris et pour les haoussa, au Niger), est celle de l'observation participante ${ }^{12}$ : il a pénétré dans les groupes grâce à sa position de moniteur d'alphabétisation, d'intermédiaire pour diverses démarches, il a appris le haoussa. Il pratique l'immersion de longue durée dans les milieux qu'il étudie, mène des entretiens; ses références pour étudier les cultures d'origine sont les travaux des ethnologues Edmond Bernus, Nicole Echard, Claude Meillassoux, etc. Il a lu les travaux de Roger Bastide et emprunte à Marcel Mauss la notion de « fait social total » : c'est ainsi qu'il définit l'immigration. S'éloignant d'une perception strictement économique et marxiste des migrations, il définit la civilisation africaine comme une « civilisation

11 « La seule façon d'aborder l'étude du vécu concret des émigrés africains nous paraît être une démarche de type ethnologique, à laquelle notre propos est de rendre ici toute son efficacité scientifique, face au délaissement dont elle fait l'objet devant la mathématisation actuelle des sciences sociales » (ibid. p. 10).

12 Il emploie le terme. 
du voyage » issue de multiples déplacements et brassages (ibid. p. 11). L'on voit bien l'élargissement de perspective par rapport à celle des auteurs précédents. Mais s'il marque un tournant, le livre de Barou est limité par bien des aspects. La nécessité qu'il ressent d'un abord ethnologique de l'immigration a son revers : elle le lie totalement à l'outil conceptuel qu'il a à sa disposition : la notion d'ethnie, dans laquelle il enferme lui-même les groupes; et la culture d'origine est implicitement pour lui quelque chose de fixe. En outre, son postulat est que l'ethnie pèse d'un poids énorme sur les Africains, plus que sur la plupart des autres immigrés présents en France. Cela le conduit à consacrer un plus grand nombre de pages au contexte nigérien qu'à la description des modes de vie en France $^{13}$. Cela le conduit aussi à envisager les transformations des statuts, des pratiques qu'il observe en France en termes de « détribalisation » ou "d'hypertribalisation », de contre-adaptation ou de substitut à la culture d'origine (cette posture est encore claire dans son article sur la recomposition en France des structures de parenté africaines publié dans un ouvrage dirigé par Martine Segalen en $1991^{14}$ ). On reste, avec Barou, dans une dualité fixe culture d'origine/culture d'accueil, cette dernière, malgré le « credo ethnologique », étant envisagée nécessairement, à son avis, en termes sociologiques. La place respective de ces deux disciplines, qu'il affirme, au début de son ouvrage, comme devant être imbriquées pour appréhender un objet aussi complexe, reste finalement problématique. On ressent bien, dans la gêne qu'il exprime à ce sujet en conclusion, qu'il existe pour lui malgré tout une barrière disciplinaire : là-bas, c'est l'ethnologie, ici aussi, mais uniquement en fonction du postulat de base qui est le sien, la permanence du cadre de l'ethnie en France. Cependant il faut reconnaître que la contestation radicale de la notion d'ethnie par des ethnologues aura lieu plus tard.

Tels sont les apports et les limites de Barou, qu'il serait injuste de réduire à ce livre : son cadre conceptuel s'est complexifié, il est sorti d'une ethnicisation trop massive et il a beaucoup diversifié son approche, publiant sur des thèmes aussi divers que l'alimentation, les femmes, l'éducation, la famille à distance, etc. On peut donc bien affirmer qu'il a ouvert à l'ethnologie le champ des études sur la migration africaine en France, sans qu'il ait été pour autant beaucoup suivi.

\section{UN TOURNANT SOCIAL ET SCIENTIFIQUE : QUESTIONS SUR UNE SOCIÉTÉ PLURICULTURELLE}

Entre l'étude de Barou (faite en 1972-1974) et sa publication est survenu, en 1974, l'arrêt de l'immigration. Il en est résulté un changement dans la composition des populations : la venue des femmes, des enfants, le regroupement familial, même si dans la réalité, les hommes seuls demeurent majoritaires, et la prise de conscience progressive de la pérennisation des immigrés en France. Comme le résume Christian Poiret (1996 : 8-9) :

13 On peut se demander alors si l'intérêt des premières études sur la migration africaine pour le travailleur immigré et non pour les étudiants ne réside pas également dans le fait que le premier semblait incarner une Afrique des traditions dont un étudiant ou un intellectuel pouvait s'être éloigné.

14 Familles africaines en France : de la parenté mutilée à la parenté reconstituée, in Segalen M. Dir., Jeux de famille : parents, parenté, parentèle, Éditions du CNRS, pp. 157-171. 
« [...] au cours des années quatre-vingt, les Français ont découvert progressivement que cet archétype du travailleur-immigré (célibataire par définition) avait femmes et enfants. Il pouvait d'ailleurs avoir plusieurs femmes et beaucoup d'enfants ».

Les pouvoirs publics commencent d'en prendre la mesure. Certes, après 1963, quelques rapports avaient été commandités par divers ministères sur des thèmes limités conformes à la perception de l'immigration dominante jusque-là (logement, main-d'œuvre, etc.). Mais après 1974, et notamment avec l'arrivée des socialistes au pouvoir en 1981, les visées assimilationnistes font place à une volonté d'amélioration des conditions de vie des immigrés en France et à la prise en compte de leurs cultures ${ }^{15}$; cependant certains traits de celles-ci sont perçus (et construits) comme problématiques, à la fois sur le plan social et sur le plan urbain (Poiret 1996 : 13). Parallèlement, les enseignants, les travailleurs sociaux, les soignants, les juristes, les personnels administratifs prennent conscience de leur ignorance des cultures de ceux qu'ils côtoient. Qu'elle soit exprimée en termes de « creuset » (Noiriel, 1988) ou de « mosaïque » (Lequin, 1988), la question de l'immigration fait naître de nombreux débats dans la société civile sur la citoyenneté, l'identité, l'intégration, la xénophobie, l'appartenance, la double culture, la société pluriculturelle, le culturalisme : tels sont, par exemple, les thèmes traités dans un numéro de la revue Esprit de juin 1985 intitulé « Français/immigrés »; débats qui se doublent de demandes de connaissances réellement politiques, devant fournir aux administrations, aux élus locaux, aux travailleurs sociaux "les éléments nécessaires à une politique d'intégration ${ }^{16}$. À partir de la décennie 1980, les pouvoirs publics ${ }^{17}$ et le secteur associatif sollicitent des recherches sur différents thèmes, demande qui perdure aujourd'hui, sur la polygamie, le logement, les parcours scolaires, les " mariages forcés », etc. Parmi bien des spécialistes (sociologues, spécialistes de sciences politiques, démographes, psychologues), c'est notamment aux ethnologues que ces demandes de connaissances sont adressées. Ceux-ci publient les résultats de leurs études dans les nombreuses revues, étatiques ou associatives, qui naissent à cette époque : Migrants-formation, émanation du CNDP créée en 1973, Migrations-santé, née à la fin des années soixante-dix, Migrations-Études, créée en 1988 par la Direction de la Population et des Migrations (DPM), Migrations-Société, née en 1989, revue du CIEMI ${ }^{18}$. En 1987, un numéro de Migrations-santé est consacré à l'excision ; à partir de 1988, Migrations-Études publie les résultats d'études embrassant un large spectre de thématiques (logement, travail, scolarité, religion, justice, vie associative, vieillissement, santé, discrimination, femmes, commerce, consommation ethnique, etc.) traitées de manière transversale (concernant plusieurs populations immigrées) ou plus

15 Le Haut conseil à l'intégration est créé en 1989.

16 Cf. sommaire du premier numéro de la revue Migrations-études, 1988.

17 Direction des populations et des migrations, ADRI, FAS, Commissariat général du Plan, MIRE, Mission du patrimoine ethnologique du Ministère de la culture, Ministère de la justice, Ministère des affaires sociales, etc.

18 Centre d'information et d'études sur les migrations internationales. 
ciblée sur les Africains ${ }^{19}$. Les revues généralistes ne sont pas en reste : dans la revue Esprit qui vient d'être citée, paraît un des premiers articles du socio-anthropologue AmadouMoustapha Diop sur les mourides en France : il ne s'agit plus uniquement de manœuvres ou d'ouvriers mais de Sénégalais musulmans - une religion qui jusqu'alors était attribuée essentiellement aux Maghrébins - travailleurs et étudiants dont la pratique religieuse, loin d'être confinée à leurs lieux de vie, se donne à voir, à Paris, jusque sur le parvis du centre Pompidou, et provoque des conversions parmi les Français (ibid. : 197-206).

Entre tous les thèmes privilégiés à cette époque, relatifs à la famille africaine, aux alliances, au traitement du corps, c'est l'excision qui a généré le plus grand nombre de demandes de la part des pouvoirs publics. Une première enquête ethnologique est suscitée à ce sujet par le Ministère des droits de la femme (1984), elle sera menée par l'ethnologue africaniste Sylvie Fainzang ${ }^{20}$; puis une seconde enquête sur « les mutilations sexuelles des fillettes africaines en France aujourd'hui » est suscitée par le syndicat enseignant FEN : elle sera réalisée par Anne Raulin, ethnologue non-africaniste qui ne poursuivra pas ses recherches sur le terrain de la migration africaine (1987) ${ }^{21}$. À l'évidence, le choix de ces « faits de société » révèle des préoccupations centrales dans les débats publics de ces années, qui dépassent largement le cadre de la question immigrée. La focalisation sur des « pratiques culturelles » perçues comme bafouant les droits des femmes à disposer de leur corps, à choisir librement leur vie et leur sexualité, tout comme l'intérêt porté à leurs initiatives d'émancipation (associations féminines) prennent place à une période où le rôle des hommes et des femmes en politique et les rapports hommes/femmes en général sont en pleine renégociation laborieuse dans la société française. Dans ce contexte, nulle autre pratique que l'excision ne pouvait mieux représenter l'altérité absolue et, par contraste, renvoyer à la société française une image presque flatteuse du traitement de ses propres femmes. Ainsi la figure de la femme africaine en France, construite sans nuances, de même que celle de la famille africaine (polygamie, " mariages forcés ») semble bien avoir rempli un rôle de repoussoir.

Dans un article paru rétrospectivement, Raulin explique les problèmes éthiques soulevés par cette recherche : comment, dans les années quatre-vingt, faire œuvre d'ethnologue quand la commande est nettement orientée dans le but de lutter contre cette pratique, que le « terrain » est saturé d'informations et de convictions ? Face à ce danger d'instrumentalisation, auquel on pourrait ajouter celui d'une reprise des travaux des ethnologues dans une perspective culturaliste lourde, qui tendrait à essentialiser les cultures étudiées, elle explique son parti pris d'ethnologue : comprendre la distance qu'il y a entre le discours des femmes et des hommes à ce sujet et leur propre tradition, décrire comment

19 Parmi les études dont la facture ethnologique est la plus marquée, citons : Quiminal C. et Bodin C. (1993) Mode de constitution des ménages polygames et vécu de la polygamie en France, $\mathrm{n}^{\circ} 41$; Diarra H., Diouf B., Fall B. et Timera M. (1997) Les jeunes filles d'origine africaine en France. Parcours scolaires, accès au travail et destin social, $\mathrm{n}^{\circ} 78$; Maguer A. et Barou J. Dir., Rigaldies F., Bazenguissa-Ganga R., Verhoeven M. et Dabo M. Coll. (1999) Modes de vie et intégration des enfants et adolescents issus de familles africaines subsahariennes, $\mathrm{n}^{\circ} 88$.

20 Une autre ethnologue, N. Échard, y participera également.

21 Raulin A. (1987) Femmes en cause. Mutilations sexuelles des fillettes africaines en France aujourd'hui, Paris, Centre fédéral (FEN), 231 p. 
ils s'y tiennent, la recomposent ou s'en éloignent. Il s'agit donc ici de prendre les femmes comme « actrices » et non sujets de leur culture (1990). Ce terme d'acteur, même s'il est rétrospectif, souligne bien le changement apporté par la perspective anthropologique dans l'étude de la migration africaine en France. Par ailleurs, cet exemple des travaux sur l'excision montre qu'en même temps qu'ils font leur recherche avec rigueur, les anthropologues de l'immigration africaine (et d'autres d'ailleurs) prennent leur place dans la cité : ils se prononcent, de façon parfois divergente, sur cette question. On trouve l'expression de ces débats dès les premiers numéros du Bulletin de l'AFA ${ }^{22}$, et cette tradition ne se dément pas $^{23}$.

Mais si dans ces études dont les thèmes sont très marqués par une demande sociale et politique, les ethnologues ont pu se revendiquer comme tels, c'est-à-dire faire œuvre de connaissance et non fournir des recettes, n'est-ce pas aussi parce que, à cette même époque, s'est développé un ensemble d'études critiques visant à montrer le caractère construit des différences sexuelles, à explorer la catégorie de genre comme une façon dont hommes et femmes sont perçus et se comportent dans des contextes sociaux et culturels donnés ? L'émergence, à partir des années soixante-dix, de ces études, nommées « études féminines », ou « études du genre », d'abord aux États-Unis puis en France, a très certainement constitué un appui scientifique stimulant pour les ethnologues abordant ces questions à propos des migrations africaines en France et leur a permis de se dégager d'un cadre idéologique qui semblait très fortement prescrit.

Un exemple significatif de l'affirmation de ce champ de recherches dans lequel ont pu être englobées des enquêtes sur la migration africaine est l'étude d'Odile Journet et Sylvie Fainzang La femme de mon mari. Étude ethnologique du mariage polygamique en Afrique et en France (1989). Il s'agit d'une recherche sur contrat financée par l'A.T.P. du C.N.R.S. « Recherches féministes et recherches sur les femmes », c'est-à-dire dans un cadre très différent de celui des études sur l'excision. Cet ouvrage est un travail charnière : il est réalisé par deux anthropologues africanistes qui pratiquent l'observation directe ; loin de toute norme, leur point de vue est de considérer la polygamie « comme une modalité particulière de socialisation de la sexualité féminine » (ibid. : 7), qu'elles étudient de l'intérieur, dans la façon dont elle est vécue quotidiennement dans les familles, dans une perspective comparative en l'observant dans divers contextes sociaux africains et dans celui de l'immigration.

L'effervescence de questions, de prises de position scientifiques et éthiques qui anime la société civile des années quatre-vingt peut être aussi illustrée par une manifestation propre aux anthropologues : le colloque international de l'AFA de 1986 intitulé «Vers des sociétés pluriculturelles : études comparatives et situations en France », ouvert par Françoise Héritier et Emmanuel Terray ${ }^{24}$. Il s'agissait clairement, contre la vision d'une France centralisatrice et unificatrice et contre un mouvement montant de xéno-

22 Association française des anthropologues.

23 On peut notamment évoquer l'engagement de Terray auprès des sans-papiers en 1996, dont il fera aussi état dans le Journal des anthropologues. On peut aussi rappeler celui de Barou, chercheur mais aussi formateur.

24 Les actes de ce colloque ont été publiés sous ce titre en 1987.

REMI 2009 (25) 3 pp. 79-100 
phobie dénoncé par Terray en 1983, de montrer la diversité culturelle de la France et son métissage. Dans son introduction, Terray invite à prendre ses distances vis-à-vis de notions comme l'identité et la différence ou comme l'ethnie et à « prendre le parti de la nuance, du scrupule, de l'érudition » (1987:40). Il en appelle aussi à la responsabilité des anthropologues : «toute approche sérieuse et rigoureuse des problèmes que posent l'immigration et le brassage des cultures suppose, sinon le concours des anthropologues, du moins le recours aux méthodes et aux techniques qui sont, par excellence, celles de l'anthropologie : (...) l'enquête prolongée sur le terrain, le séjour à l'intérieur des communautés concernées, l'observation directe, le dialogue approfondi avec tous les acteurs de la vie sociale ». Il déplore que les anthropologues soient à ce sujet encore " assez loin du compte » et la tendance de la profession à considérer comme " de second rang " les études menées à Vénissieux ou à Gennevilliers (ibid. : 41). Il invite à redéfinir les objets de recherche et les investissements de la discipline, et à ne pas abandonner le terrain aux urbanistes et aux sociologues du travail.

Dans ce colloque, peu de personnes ont traité de la migration africaine : un article à trois voix, comparant situations maliennes et portugaises, défend la notion de « bi-localisation », c'est-à-dire de projets familiaux investissant simultanément deux espaces ; mais l'allusion aux Africains y est très fugace ${ }^{25}$. Deux articles leur sont directement consacrés, qui traitent du développement de pratiques magico-religieuses ouest-africaines dans le quotidien français ${ }^{26}$. À travers ces thèmes se fait jour une vision nouvelle des cultures immigrées, à la fois dans l'interaction avec les cultures d'origine et non plus dans une juxtaposition entre ici et là-bas, et, en France même, par la prise en compte du brassage évoqué par Terray. On en trouve aussi certains exemples dans la revue Hommes et Migrations.

Cette prise de position du colloque a donné une légitimité théorique aux études sur l'immigration faites par des anthropologues. Mais a-t-elle été entendue ? En tout cas, de nouvelles études, peu nombreuses il est vrai, ont été produites. Cependant il faut constater que la plupart ont été publiées soit, très rarement, dans des livres, soit, beaucoup plus fréquemment, dans des revues telles celles citées plus haut ${ }^{27}$. Deux explications de ce fait peuvent être avancées. D'une part, cantonner délibérément à ces publications sans reconnaissance dans la communauté scientifique et sans grande diffusion l'étude de certains thèmes très sensibles (mariage « forcé », polygamie) permettait de les évoquer, de s'en saisir dans la sphère politique tout en les maintenant dans une certaine invisibilité ; ceci à la notable exception du livre de Journet et Fainzang dont il vient d'être question ${ }^{28}$ ainsi

25 Cordeiro A., Gonin P. et Quiminal C., Les positivités de la mise en contact de cultures différentes, ibid., pp. 490-494.

26 Ba S.-M., Réflexions sur un devin peul dans le quotidien français, ibid., pp. 351-354 ; Kuczynski L., Retour d'affection : quotidien français et maraboutage, ibid., pp. 355-361.

27 Ce qui est encore partiellement le cas actuellement.

28 S. Fainzang a également publié sur l'excision dans la revue canadienne Anthropologie et sociétés $\left(1985\right.$, vol $\left.9 n^{\circ} 1\right)$ et sur la polygamie dans un ouvrage collectif intitulé Côté femmes. Approches ethnologiques (L'Harmattan 1986). 
que, plus tard de l'étude de Poiret sur les familles africaines (1996) ${ }^{29}$. D'autre part, les revues françaises d'anthropologie n'offraient pas de tribune à ces recherches, constatation qui découle directement de l'illégitimité de celles-ci aux yeux des africanistes, telle que nous l'évoquions en introduction, de même que des anthropologues en général ${ }^{30}$, illégitimité déplorée par Terray - et corollairement, du petit nombre de personnes qui s'y sont engagées. Le résultat du comptage des articles sur ce domaine dans les revues d'anthropologie jusqu'à aujourd'hui est édifiant : 5 articles dans les Cahiers d'études africaines (dont le premier, en 1976, de Barou sur l'émigration mais, de façon significative, vue du village haoussa d'où sont originaires ceux qu'il a étudiés en France) ${ }^{31}$; tout au plus 3 articles et plus tardifs (encore Barou en 1990) pour le Journal des Africanistes ; aucun article pour la revue Systèmes de pensée en Afrique noire. Cette tendance se confirme dans les revues plus généralistes : 4 articles dans L'Homme, dont le premier en 1997, 2 dans Ethnologie française, (où plusieurs numéros sont pourtant consacrés à l'immigration), 8 dans le Journal des anthropologues (où Catherine Quiminal est très présente), 4 dans les Cahiers de sciences humaines/Autrepart, 3, très tardivement, dans Sciences sociales et santé. De façon significative, les études sur la migration africaine en France sont présentes dans les comptes rendus de L'Homme, des Cahiers d'études africaines, et dans la rubrique « Ethnologie au jour le jour » du Journal des anthropologues, c'est-à-dire dans des rubriques secondaires. Concernant le Journal des africanistes et les Cahiers d'études africaines, il faut pourtant remarquer que les migrations intérieures à l'Afrique y sont abondamment traitées sans que ces études, initiées dès les années cinquante et soixante par les travaux de Jean Rouch et Monique Gessain, soient relayées par des études consacrées à la migration africaine en France. De même, dès la première livraison des Cahiers d'études africaines en 1960, sans doute à la suite des travaux de Balandier, la ville est bien présente de même que ses marges et de nombreux thèmes de la modernité : entreprises, femmes libres, etc. : preuve supplémentaire que les barrières disciplinaires restent très marquées et que, en dépit des remarques de Terray, l'africanisme s'est longtemps arrêté aux frontières du continent. De fait, c'est en grande partie en marge de l'africanisme que se sont développées les études anthropologiques sur la migration africaine en France, voire en marge de l'anthropologie « patentée » en général, comme le montre le dépouillement des revues.

Il faut mettre à part deux revues interdisciplinaires spécifiquement consacrées aux migrations : la Revue Européenne des Migrations Internationales (née en 1985), qui publie en 1994 un premier numéro spécial consacré aux migrations africaines : on y trouve

29 Cependant dans une analyse rétrospective de son travail, Journet remarquait que si elle avait su que, quelques années plus tard, la polygamie serait érigée en « comportement anti-social », elle-même et Fainzang auraient peut-être abordé autrement la question (communication orale).

30 Parmi lesquels les africanistes avaient un rôle influent.

$31 \mathrm{Il}$ est impossible de citer tous les articles des revues recensées. Nous nous contentons d'indiquer ceux qui sont parus dans les Cahiers d'études africaines : en 1976, Barou J. : " L'émigration dans un village du Niger »; en 1981, Salem G. : « De la brousse sénégalaise au Boul'Mich : le système commercial mouride en France »; en 2001, Gueye A. : " De la religion des intellectuels africains en France. L'odyssée d'un référent identitaire »; en 2005, Deshusses M. : « Du confiage à l'esclavage ; 'petites bonnes' ivoiriennes en France »; en 2008, Kuczynski L. : « Attachement, blocage, blindage. Autour de quelques figures de la sorcellerie chez les marabouts ouest-africains en région parisienne ». Encore ce recensement est-il très large puisque Salem G., dont, il est vrai, l'article a beaucoup nourri les anthropologues, est géographe.

REMI 2009 (25) 3 pp. 79-100 
deux articles de jeunes ethnologues dont l'un consacré à la migration camerounaise en France (Sophie Bouly de Lesdain) et l'autre aux mères soninké et leurs enfants à Paris (Claire Laudereau) $^{32}$; quelques autres articles d'ethnologues paraîtront dans cette revue largement dominée par les sociologues, les géographes et les démographes. Autre revue à mettre à part : Hommes et migrations, datant de $1950^{33}$, publication au statut associatif. Comme on l'a vu, le premier article consacré aux «travailleurs africains » date de 1961 ; mais dans deux numéros spéciaux consacrés aux Africains noirs en France en 1990 - dont l'un, traitant de la « vie culturelle », marque bien l'extension des perspectives par rapport à la période antérieure -, on trouve les signatures de Barou ; Quiminal ; Diop ; Meillassoux, etc. Les ethnologues des migrations ont publié et publient dans cette revue, sans doute parce qu'elle est explicitement dévolue au thème et constitue une des seules tribunes qui accueillent leurs recherches tout en constituant pour la plupart d'entre eux une sorte de tremplin ; cependant Hommes et migrations a peu à peu acquis une place dans le champ scientifique.

Si l'africanisme «patenté », a longtemps négligé les migrations africaines en France, en revanche il faut noter le rôle, dans ce domaine, de l'anthropologie urbaine, tout aussi important que celui des études féminines. L'influence de cette branche de l'anthropologie nous semble multiforme. En premier lieu, l'étude des groupes minoritaires dans la ville, qu'il s'agisse de migrants, de minorités sociales ou professionnelles, a longtemps constitué l'une de ses thématiques privilégiées ; cependant la focale portée sur la ville et ses habitants a permis de décentrer la perspective sur ces minorités et de s'écarter des fondamentaux constitués de longue date par les spécialistes de l'Afrique ou de l'Asie. L'anthropologie urbaine a aussi contribué à sortir l'anthropologie des migrations du paradigme ethnique ; elle a légitimé l'étude du proche et a renouvelé le regard sur les immigrés : loin qu'il n'y ait chez « ces gens-là » ${ }^{34}$ que du malheur ou du vide (perspective de Abdelmalek Sayad) et de l'anomie, ils sont montrés comme porteurs d'une culture considérée dans sa dynamique, tantôt maintenue, valorisée, tantôt brassée, réinterprétée au contact de toutes celles qu'ils côtoient dans les villes. En outre, l'anthropologie urbaine a aussi conduit à inventer des méthodes de recherche sur des groupes disséminés dans l'espace (et non regroupés en quartiers ou en foyers) et à prendre en compte des réseaux multiples qui s'entrecroisent. Si tous les anthropologues travaillant sur les migrations africaines (et d'autres) sont loin de se revendiquer explicitement comme anthropologues urbains, il n'en reste pas moins que sa perspective et ses méthodes ont largement irrigué ce champ de recherches.

\section{DIVERSIFICATION DES FIGURES ET DES TERRAINS}

Dans le développement qui précède, on a vu peu à peu apparaître plusieurs éléments : la considération de l'immigré comme acteur, celle de la « bi-localisation »,

32 Bouly de Lesdain S. (1994) « Migration camerounaise et sorcellerie en France », vol 10, 3, pp. 153-173 ; Laudereau C. (1994) «Les mères soninké et la santé de leurs enfants à Paris », vol 10,3 , pp. $175-188$.

33 Pour une très rapide histoire de cette revue, voir la note 7.

34 Titre d'un ouvrage de C. Pétonnet, l'une des pionnières de l'anthropologie urbaine en France. 
enfin la prise en compte du remodelage, de la reformulation des pratiques africaines dans l'environnement français, des multiples passerelles avec celui-ci : tous ces thèmes vont s'affirmer à partir de la fin des années quatre-vingt et dans les années quatre-vingt-dix, deux mille, et vont montrer les cultures africaines dans leur dynamique ${ }^{35}$. Cette ouverture du regard, conjuguée à l'évolution de la migration africaine elle-même a éloigné l'image du travailleur exploité pour faire apparaître d'autres figures et d'autres rôles sociaux ${ }^{36}$.

Le champ des études s'étend. À la suite des travaux de Fainzang et Journet (1988) et Fainzang (1991) ${ }^{37}$, l'intérêt pour les migrations féminines (Nicollet, 1992) et pour la famille africaine en France (Poiret, 1996) se développe chez les sociologues. Ces thèmes seront traités aussi par des psychologues, psychiatres, ethnopsychiatres et des anthropologues ou socio-anthropologues.

Dans les années quatre-vingt-dix, est renouvelée une thématique ancienne : l'intérêt pour les troubles psychologiques du migrant africain, étendu aux membres de la famille (femmes et enfants) puis, plus tardivement, aux troubles physiques ; thématique ancienne puisqu'elle faisait l'objet d'études dans la revue Psychopathologie africaine dès sa fondation à Dakar (1965), non à propos de migrants outre-mer mais de ruraux installés dans les villes africaines ; cependant, dès 1968, un article analyse des dossiers d'Africains noirs hospitalisés à Sainte-Anne de 1946 à $1960^{38}$. On se souvient, de même, que dès 1965, les Cahiers nord-africains faisaient une grande place à la « pathologie des Noirs transplantés ", remarquant à ce propos que "le médecin 'occidental' doit alors remettre en question sa propre représentation culturelle de la maladie » (op.cit. : 8). Les années quatre-vingt-dix voient fleurir des revues spécialisées et de nombreux articles dévolus à ces questions : la Nouvelle Revue d'Ethnopsychiatrie créée en 1983 se saisit de la problématique des troubles psychologiques de l'enfant africain dès 1987, suivie par Psychopathologie africaine en 1993. Cette dernière revue consacre en 1991, un numéro spécial au thème général « Migrations et Psychopathologie» dans lequel les Africains sont représentés et pour la première fois, la mère migrante africaine ${ }^{39}$. Cette même année, la Nouvelle Revue d'Ethnopsychiatrie s'intéresse à l'excision et poursuivra sur la question de la dépression. Dans la revue L'Autre, créée en 2000, les migrants africains apparaissent parmi d'autres et seuls trois articles consacrés à la maladie, à la scolarisation et au

35 Il faut rappeler néanmoins que dès 1977, A. Adams évoquait les gens du fleuve en tant qu' «acteurs historiques en puissance » $(1977$, p. 202).

36 Une illustration de ce fait : rompant avec les représentations traditionnelles, la couverture du n ${ }^{\circ} 67$ (1997) de la revue Politique africaine intitulé « La France et les migrants africains » présente un Africain à l'air soucieux, dans une rue de Paris. Il porte un jean et un pardessus, une serviette de cuir et un journal. La légende mentionne : Place Saint-Michel, Paris 1996.

37 Sexualité et reproduction chez les Africaines immigrées soninké et toucouleur vivant en ménage polygamique, Sciences sociales et santé 9 (4), pp. 88-109.

38 Diop B. (1968) Sur la transplantation négro-africaine en France, Psychopathologie africaine 1968, IV, 2, pp. 227-276.

39 Psychopathologie africaine, vol. XXIII, 3, 1990-1991.

REMI 2009 (25) 3 pp. $79-100$ 
débat politique sur la polygamie les concernent spécifiquement ${ }^{40}$. On ne développera pas, ici les débats et divergences assez connues qui s'expriment, dans ces revues, entre les différentes tendances qui se partagent ce champ ; sans alimenter à eux seuls ces débats, les migrants africains en sont souvent le centre. Dans sa version ghettoïsante et simplificatrice débouchant sur un " véritable programme [politique] de gestion de l'immigration » (Fassin, 2000 : 237), c'est l'ethnopsychiatrie, incarnée par la personnalité médiatique de Tobie Nathan qui a principalement fait l'objet de controverses publiques et scientifiques ; dans un article implacable, Didier Fassin en résume les enjeux par une mise en perspective de l'ethnopsychiatrie avec la période coloniale, dénonçant « l'absence de tout travail de connaissance anthropologique » $(2000: 241)$ de ce mouvement et l'enfermement des immigrés dans la culture d'origine qu'on leur assigne, au mépris de leur vie en France. Cette position extrême va à l'encontre de la perception de l'ouverture, de la renégociation des identités et des rôles des migrants et de leur descendance que commencent d'étudier bien des ethnologues.

En effet, c'est en rendant compte d'une bien plus grande complexité qu'anthropologues et socio-anthropologues traitent de l'identité des jeunes issus de l'immigration africaine et pour certains plus largement de la famille (Timera ${ }^{41}$, Quiminal ${ }^{42}$, Pradelles de Latour ${ }^{43}$ ), de la femme, de la maternité, du maternage et de la socialisation de l'enfant (Rabain-Jamin et Wornham ${ }^{44}$; Fainzang ${ }^{45}$; Quiminal ${ }^{46}$, etc.), de la santé et également des rapports de sexe en situation de migration au sein du couple et plus globa-

40 Il est impossible, dans le cadre de cet article, d'indiquer toutes les parutions de cette époque. Nous nous contenterons, à titre d'exemple, d'en indiquer un pour chacune des revues citées : Ondongo J. (1987) Enfant-ancêtre, enfant-voyage. La pathologie d'un enfant comme seul signe de la difficulté d'adaptation d'une famille de migrants, Nouvelle Revue d'Ethnopsychiatrie, n 8/9, pp. 181-192 ; Ortigues M.-C. \& E. (1993) Pourquoi ces mères indifférentes ? ou Comment faire la part du culturel ?, Psychopathologie africaine, vol. XXV, 1, pp. 5-31; Moro M.-R. et al. (2006) Les filles et les fils de la République sont aussi des enfants de familles polygames, L'autre, 7(1), pp. 5-10.

41 Plusieurs articles, par exemple : Les jeunes issus de l'immigration soninké face aux identités familiales et communautaires, Migrants-formation, 1992, 91, pp. 90-112.

42 Ici encore, plusieurs articles, et notamment : Familles immigrées entre deux espaces, in Fassin D., Morice A. et Quiminal C. Éds. (1997) Les lois de l'inhospitalité. La politique de l'immigration à l'épreuve des sans-papiers, Paris, La Découverte, pp. 67-80. Dès 1992, un numéro interdisciplinaire de la revue Migrants-formation (91) intitulé « Familles africaines » paraît avec les signatures de plusieurs de ces anthropologues.

43 Pradelles de Latour Ch.-H. (2001) Clivages et dérapages. Première et deuxième générations d'Africains en banlieue parisienne, L'Homme, 157, pp. 151-166.

44 Transformations des conduites de maternage et des pratiques de soin chez les femmes migrantes originaires d'Afrique de l'Ouest, Psychiatrie de l'enfant, 23, 1990, pp. 287-319.

45 Sexualité et reproduction chez les Africaines immigrées soninké et toucouleur vivant en ménage polygamique, Sciences sociales et santé 9 (4), 1991, pp. 88-109.

46 Quiminal C. et Bodin C. (1991) Le long voyage des femmes du fleuve Sénégal, Hommes et Migrations, 1141, pp. 23-26. 
lement au sein de la famille ${ }^{47}$. Concernant les troubles physiques, à côté d'approches en termes juridiques (santé et lois sur l'immigration), les recherches des anthropologues se centrent sur des pathologies particulières : la drépanocytose, traitée par Doris Bonnet, anthropologue africaniste ${ }^{48}$, le saturnisme infantile dans les familles d'origine sénégalaise et malienne vivant en région parisienne, analysé par Nadia Rezkallah et Alain Epelboin $(1997)^{49}$ et surtout le sida abordé dans des revues thématiques telle Sciences sociales et santé mais aussi dans $L$ 'Homme ${ }^{50}$. Constatant le long silence français sur cette question, Fassin remarque qu'entre deux explications de l'épidémie, l'une par la « culture » des Africains immigrés, l'autre par la précarité de leurs conditions de vie, on s'est peu interrogé « sur la manière dont la condition d'immigré interfère avec la condition de malade et sur la signification de la relation entre les deux » révélatrice, selon lui, des « fondements moraux de notre monde » $(2001: 160)$ - perspective qui montre bien la nécessité de sortir des analyses culturalistes et le pouvoir critique de l'anthropologie à l'égard de problématiques formulées en amont.

Cependant les thèmes qui viennent d'être énoncés, clairement inscrits à l'agenda politique tant national qu'international et dans les débats de société en France ${ }^{51}$, contrastent avec d'autres qui commencent d'être traités, comme les « sans-papiers » : ceux-ci se présentent plus nettement comme l'expression d'un contre-pouvoir politique des chercheurs sur la question immigrée en France.

Mais revenons sur les travaux de certains chercheurs. Ceux de Catherine Quiminal (1991), Mahamet Timera (1996), Christophe Daum (1998) ouvrent de nouvelles perspectives en montrant les migrants acteurs de leur vie en France comme du développement de

47 Voir les références note 19, auxquelles on peut ajouter : Quiminal C. (2000) Construction des identités en situation migratoire : territoire des hommes, territoire des femmes, Autrepart, 14, pp. 107-120.

48 Bonnet D. (2005) Diagnostic prénatal de la drépanocytose et interruption médicale de grossesse chez les migrantes africaines, Sciences Sociales et Santé, vol. 23, n² 2, pp. 49-65.

49 Cet ouvrage mérite d'être signalé en raison de son approche résolument ethnologique et du suivi de l'enquête dans la durée ; il entre avec précision dans le quotidien de dix familles africaines et est l'un des premiers à traiter des enfants. Les auteurs tentent d'articuler ce qu'ils interprètent comme l'adaptation à « un nouvel écosystème » de pratiques culturelles observées en Afrique (par exemple la géophagie) avec les problèmes sociaux rencontrés par les familles à Paris. La production qui suivra sur ce thème critiquera cette approche, considérée comme trop culturaliste ; des travaux démontreront que, contrairement au discours institutionnel et étatique s'abritant derrière des interprétations mettant en avant la culture des migrants, discours qui prévaudra jusqu'au début des années deux mille, le saturnisme est un symptôme plus social (familles précarisées sur tous les plans) que culturel : c'est du côté des conditions sociales d'existence des migrants et donc du politique que l'analyse doit être conduite, plutôt que de celui de la culture et de « mauvaises pratiques » de ces migrants (Naudé A.-J. (2000) Le saturnisme, une maladie sociale de l'immigration, Hommes et migrations, $\mathrm{n}^{\circ} 1225$, pp. 13-22; Fassin D. (2003) Naissance de la santé publique : deux descriptions de saturnisme infantile à Paris (1987-1989), Genèses 53, pp. 139-152).

50 Notamment les travaux de D. Fassin (1999) L'indicible et l'impensé : la « question immigrée » dans les politiques du sida, Sciences Sociales et Santé, vol 17, n 4, pp. 5-36; cf. aussi vol. 19, n ${ }^{\circ} 4$ (2001), ainsi que D. Fassin (2001). Une double peine. La condition sociale des immigrés malades du sida, L'Homme, 160.

$51 \mathrm{Ce}$ dont attestent les financements des études comme les lieux de publication. 
leur village, notamment par le biais des associations et des caisses villageoises ; ils s'intéressent ensuite à l'engagement des femmes africaines migrantes dans la société française et dans leur pays de départ ${ }^{52}$, aux modifications des statuts sociaux des immigrés dans leur société d'origine ${ }^{53}$, etc. L'appartenance de ces migrants est multiple, ce que dit nettement le titre du livre de Quiminal : Gens d'ici, gens d'ailleurs (1991) et leur citoyenneté, de même que les rapports de sexe se redéfinissent en interaction entre ces espaces.

Les travaux précurseurs de Quiminal font écho à ceux d'Alain Tarrius qui développe, à propos d'autres migrations, l'idée non plus de lieux fixes, ici et là-bas, mais de « territoires circulatoires ». Tarrius montre, en outre, que la démarche anthropologique est la plus propre à saisir cette complexité. Si, pourtant, le rendu ethnographique de ces travaux laisse parfois le lecteur ethnologue sur sa faim, ils ont fait progresser la connaissance des migrations africaines en montrant que les identités ne sont pas figées mais négociées dans plusieurs espaces, en interaction les uns avec les autres. On est loin des problématiques politiques et de la réduction de la migration à des enclaves ou à la figure du travailleur sahélien exploité et traqué. Pour reprendre les termes de Tarrius (1993), le couple « immigration/insertion a été remplacé par le couple « migration/territoire ». Et c'est bien aussi le vocabulaire employé par les chercheurs qui se modifie, puisqu'ils parlent désormais moins d'immigrés que de migrants.

D'autres figures apparaissent à la faveur de nouvelles recherches consacrées à des migrants originaires d'autres parties de l'Afrique où ceux-ci sont étudiants, commerçants, cadres, femmes, etc. On était déjà sorti de l'étude privilégiée des Soninké et Toucouleurs de la vallée du fleuve avec la thèse de Diop sur les Manjaks (1981), majoritairement chrétiens, en tout cas peu musulmans et ne vivant pas dans les foyers ${ }^{54}$. Dans les années quatre-vingt-dix, Bouly de Lesdain traite des femmes camerounaises qui, cas de figure jusque-là peu étudié, sont présentes en France avant le regroupement familial (1999) ; Justin-Daniel Gandoulou dès 1984 et Guy Boudimbou (1991) étudient les Congolais. Ces études montrent des migrants entrepreneurs, commerçants, qui s'habillent, s'amusent, élèvent leurs enfants, ont des pratiques religieuses ${ }^{55}$. L'entreprenariat africain est le thème qui a suscité le plus de recherches - émergence tardive par rapport à l'étude de l'entreprenariat d'autres groupes comme les Asiatiques de Paris ou les Pakistanais de Londres, surtout au regard de l'ancienneté de ces pratiques africaines. Ces recherches, menées depuis les années quatre-vingt, ont d'abord été nourries par les études américaines concernant l'« ethnic business » (Bonacich, Light, etc.) ; elles s'orientent ensuite vers la dimension urbaine globale de ces activités. On pense à tous les travaux sur Marseille (Bava, 2002) et à ceux de Bouly de Lesdain (1999) : celle-ci montre que certaines femmes camerounaises commerçantes sont d'anciennes étudiantes reconverties dans des réseaux d'approvisionnement internationaux de produits exotiques vendus dans cette « centralité immigrée »

52 Quiminal C. (1997) Un réseau d'associations de femmes africaines, Hommes et Migrations, $\mathrm{n}^{\circ} 1208$, pp. 24-30.

53 Timera M. (2001) Les migrations des jeunes Sahéliens : affirmation de soi et émancipation, Autrepart, 18, pp. 37-49.

54 Son ouvrage a été publié en 1996.

55 Mais il est vrai qu'il manque toujours une étude sur les diplomates, hauts cadres d'entreprise, avocats, etc. qui d'ailleurs remettrait probablement sur le métier l'idée du découpage par origine. 
internationale $^{56}$ qu'est le quartier Château Rouge. Et c'est bien, à travers les trajectoires individuelles et collectives des migrants, aussi de fabrique de la ville dont il s'agit, comme ici d'un quartier devenu un carrefour des mobilités les plus diversifiées. Dans cette étude apparaît aussi la prise en compte de l'internationalisation des activités économiques et de la généralisation de ces mobilités : cette troisième perspective oriente largement les études dès le milieu des années quatre-vingt-dix ${ }^{57}$. Outre ces travaux sur le commerce, poursuivis de façon soutenue jusqu'aujourd'hui, un autre exemple du renouvellement des thèmes est l'étude originale de Gandoulou (1984) : dans Entre Paris et Bacongo, deux espaces indissociables, il dévoile un petit groupe d'aventuriers congolais nommés « sapeurs » dont la migration vers Paris ne doit rien à la misère économique mais est conçue comme un voyage initiatique ; elle leur permet de se constituer, à partir de vêtements griffés, un capital matériel et symbolique qui feront d'eux, à Bacongo, des « Grands ». Ces études sont résolument anthropologiques par les thèmes abordés : religion, gestion de l'infortune, commerce, parenté, alliance, espace habité, etc. mais plus encore par la méthode d'observation employée, les référents bibliographiques et conceptuels, le rendu dense dans l'écriture. L'une des notions souvent employées dans ces travaux est celle de bricolage, proposée par Claude Lévi-Strauss et modelée par Roger Bastide (1970).

Pourquoi ce traitement anthropologique de la question de l'immigration africaine semble-t-il s'accélérer à partir des années quatre-vingt-dix ? Outre la visibilité des migrants africains avec l'arrivée des femmes, des enfants, le développement des flux migratoires en provenance d'Afrique Centrale, les contacts plus étroits avec l'ensemble de la société française et les initiatives engagées, c'est le caractère peu heuristique de la problématique étroite de l'intégration, auquel on peut ajouter le caractère peu opératoire de cette perspective en matière politique, qui a permis de laisser une place aux recherches anthropologiques. C'est sans doute en retournant à l'approche ethnographique longue et minutieuse, et à l'approche biographique que les études sur la migration africaine ont pu diversifier et complexifier les thèmes, sortir du carcan des problématiques convenues, ouvrir les études à d'autres migrations africaines et à bien d'autres espaces ${ }^{58}$. Sans doute aussi, l'influence des traditions académiques anglo-saxonnes commence-elle à se faire sentir. Cette perspective anthropologique amène aussi à revoir les frontières et les modalités de l'ethnicité : bien loin de considérer les migrants africains comme constituant des isolats culturels, certaines études s'attachent à souligner les liens et les multiples interactions avec la société

56 Le terme est de J.-C. Toubon et K. Messamah (1990) Centralité immigrée. Le quartier de la Goutte d'Or, Paris, L'Harmattan, CIEMI.

57 Pour toutes les études sur le commerce dans la migration africaine, on peut renvoyer à l'excellente synthèse introductive présentée dans la thèse de Julie Garnier (2006) Pratiques de l'échange, circulations et stratégies spatio-temporelles : la mise en scène des commerçants africains en milieu urbain, pp. 2-15 - encore une thèse dite de sociologie soutenue devant un jury partiellement d'ethnologues.

58 Timera résume bien les failles de certaines approches antérieures : «Une méthode d'analyse centrée sur le groupe et les pratiques de groupe et très peu sur l'acteur individuel, une certaine dépendance par rapport à des problématiques militantes et 'développementalistes' sur un sujet politiquement et idéologiquement chargé et, enfin, un relatif emprisonnement sinon une forte empathie et sympathie avec le discours des migrants expliquent jusqu'à un certain point ces biais dans notre approche » (2001, op.cit., p. 41). 
globale, en matière commerciale comme en matière religieuse. Ainsi les marabouts ouestafricains venus en France étudiés par Liliane Kuczynski, souvent d'anciens travailleurs reconvertis en petits entrepreneurs religieux spécialistes du traitement de l'infortune et de l'acquisition de gains de toutes sortes, ont pu très tôt s'appuyer sur une clientèle sortant très largement des milieux africains et ont fondé une part de leur légitimité sur le respect des lois françaises. Cette recherche, menée au début des années quatre-vingt-dix, documentée à plusieurs sources sur le rôle et les pratiques des marabouts en Afrique de l'Ouest, a été volontairement menée exclusivement en terrain parisien ; prenant le contre-pied du point de vue alors habituel des études concernant l'Afrique, elle se fondait sur l'hypothèse que l'existence en France de ces figures de l'islam ouest-africain avait en elle-même une richesse à dévoiler, dans les innovations, les liens tissés sur place, et l'originalité des parcours individuels qu'elle révélait - ce qui n'excluait certes pas la prise en compte des multiples réseaux entretenus avec les pays d'origine (Kuczynski, 2002).

Cependant une bonne part des recherches récentes prend pour terrain des espaces multiples, pratique initiée depuis longtemps par Barou, Quiminal et Tarrius notamment, puis théorisée par des chercheurs américains (en particulier George Marcus, Arjun Appaduraii $)^{59}$. Qu'il s'agisse des réseaux commerciaux des migrants africains ou du déploiement des espaces religieux mourides dans la migration $\left(\mathrm{Bava}^{60}\right)$, des pratiques féminines d'épargne (Semin, 2007), des interactions entre « ici » et « là-bas » concernant les rituels funéraires (Petit, 2002), de l'influence des migrants sur la vie politique sénégalaise (Salzbrunn, 2002) pour ne citer que quelques exemples, toutes ces études prennent acte de la transnationalisation de l'expérience migratoire africaine, qui ne se déploie souvent plus entre deux mais plusieurs espaces, non seulement lieux de départ et d'arrivée provisoire mais lieux intermédiaires d'attente ou de renouvellement ${ }^{61}$. Des domaines tels la parenté ou la famille sont aussi traités dans une telle perspective : s'agissant des dynamiques familiales, éducatives et matrimoniales à l'œuvre entre le Mali et la France, c'est à partir des notions de « circulation », de « famille dispersée » et de " dette migratoire » qu'Élodie Razy analyse les effets de la migration sur les processus continus de modelage des identités à différents moments du cycle de vie (2007) ; en outre l'observation de quelques « retours »- le pluriel signifiant qu'il s'agit en fait de plusieurs allersretours entre France et Afrique (ici le Mali) - permet de dégager les valences différentes que revêtent ces circulations selon qu'il s'agit d'hommes, de femmes ou d'enfants, ces derniers étant souvent nés en France, et, démentant toute assignation identitaire préétablie, amène à la constatation frappante que « le lieu du retour se déplace avec celui qui circule :

59 On trouvera une analyse détaillée de cette anthropologie multi-située et de ses implications méthodologiques dans l'article de Jeanne Semin.

60 Nombreux articles, notamment : De la baraka aux affaires. Ethos économico-religieux et transnationalité chez les migrants sénégalais mourides, Revue Européenne des Migrations Internationales, vol. 19 (2), 2003, pp. 69-84.

61 Mais l'approche anthropologique contribue à montrer que bien souvent ces distinctions se brouillent. Voir à ce sujet l'article de S. Bava (2005) « Reprendre la route » : les relais mourides des migrants sénégalais au Niger, in Laurent Fourchard, André Mary et René Otayek Dir., Entreprises religieuses transnationales en Afrique de l'Ouest, Paris, Karthala, pp. 73-88; et celui de M. Timera (2009) Aventuriers ou orphelins de la migration internationale ? Nouveaux et anciens migrants subsahariens au Maroc, Politique africaine, $\mathrm{n}^{\circ}$ 115, pp. 175-195. 
éternel retour $»^{62}$.

Cette approche «multi-située », où le réseau a souvent remplacé la bi-localisation, semble actuellement dominante dans les études d'anthropologie de la migration africaine, qui en affinent le concept et la pratique. Sans doute cette ouverture scientifique trouve-t-elle un écho dans la prise en compte politique non plus seulement des populations sur place mais aussi des flux migratoires ${ }^{63}$. Elle n'exclut cependant pas d'autres points de vue plus « sédentaires », un retour au « local» sur des thèmes renouvelés : le travail de Frédérique Fogel s'intéresse à la façon dont on " fait famille » en situation migratoire et analyse le rôle de la mémoire dans la transmission de la parenté (2007).

Mais il semble que la vision plutôt optimiste, dynamique, créative, « entreprenariale » de la migration africaine telle qu'elle est analysée depuis les années quatrevingt-dix, commence à céder la place, à l'occasion d'événements tragiques survenus dans les années deux mille cinq, deux mille $\operatorname{six}^{64}$, à d'autres figures plus sombres : celles des " laissés pour compte de la migration ${ }^{65}$, des expulsés, des réfugiés, des sans-papiers, des échoués $^{66}$, et inversement, celles de tous ceux qui profitent de la migration. Cependant, tandis que Bredeloup revient sur la figure multiforme de l'aventurier actuellement mise en valeur (2008), une récente livraison de Politique africaine, intitulée « Migrants ouestafricains. Miséreux, aventuriers ou notables ? » tente de démonter quelques stéréotypes, en particulier une vision misérabiliste des migrants ${ }^{67}$ et l'idée politique, présentée comme salvatrice, du co-développement. Plusieurs travaux ethnographiques récents révèlent, en effet, une réalité plus complexe : Thomas Fouquet montre que les véritables « miséreux » sont ceux qui ne réussissent pas à partir ; il analyse le désir d'ailleurs de ceux-ci et leur imaginaire des pays dont ils rêvent (2007); Emmanuelle Bouilly décrit les enjeux féminins de la migration masculine derrière les positions anti-migratoires d'un collectif de femmes sénégalaises $(2008)^{68}$. Ces deux exemples montrent en outre que traiter de la migration ne signifie plus seulement étudier les groupes ou les individus présents en France, ni même les suivre dans les différents espaces qu'ils traversent, mais aussi en revenir aux lieux d'origine où s'élaborent et se reconfigurent les projets migratoires et y analyser le rôle des non migrants.

62 Razy E. (2006) De quelques « retours soninké » aux différents âges de la vie. Circulations entre la France et le Mali, Journal des Anthropologues, 106-107, pp. 337-354.

63 Cependant il faut rappeler que les préoccupations du monde de la recherche et celles du monde politique en matière d'immigration ne coïncident pas le plus souvent, comme le montrent la laborieuse naissance de la Cité Nationale de l'Histoire de l'Immigration et le tollé récent des chercheurs provoqué par la tentative du gouvernement français de centraliser les recherches sur les migrations.

64 Naufrage de pirogues de migrants, politiques de durcissement en Europe, incidents de Ceuta et Melilla notamment.

65 Expression empruntée à Timera, op.cit., 2009, p. 195.

66 On peut se demander si la figure du sans-papiers, puis celle du réfugié, ne viennent pas remplacer, dans l'engagement des chercheurs, celle du travailleur exploité des années soixante-dix.

67 Celle qui avait déjà cours à propos du « travailleur » dans les années soixante-dix.

68 On peut citer aussi le $\mathrm{n}^{\circ} 3$ de la revue en ligne Asylon(s) du réseau scientifique Terra : Migrations et Sénégal : pratiques, discours et politiques, coordonné par E. Bouilly et N. Marx, mars 2008. 


\section{CONCLUSION}

Le traitement de la migration africaine en France et à partir de ce pays constitue sans aucun doute une figure emblématique à la fois du développement des politiques publiques concernant les migrations et de l'histoire de l'anthropologie française. Dans ce champ particulièrement sensible, l'anthropologie a réussi peu à peu à faire sa place. Contribuant à complexifier les figures du migrant, elle a notamment sorti les travaux menés dans ce domaine d'un culturalisme posé a priori et a apporté bien des nuances à une ethnicisation trop lourde. Dans ce sens, on peut dire que, paradoxalement, c'est en les sortant de l'africanisme classique - permettant sans doute à celui-ci de se renouveler qu'elle s'est frayé un chemin dans les études africaines.

Le cadre d'étude a éclaté : traiter l'immigration en France consiste aujourd'hui pour nombre de chercheurs à tenir compte de la mobilité vécue par les migrants et à prendre pour terrain tant les villes françaises que les villes italiennes, espagnoles, américaines ou chinoises, les quartiers de Dakar, les espaces intermédiaires ou alternatifs tels les ports du Maroc ou de Mauritanie où les migrants étendent leurs réseaux, sans oublier les lieux imaginaires dans lesquels ils se projettent. Certes, le développement de la perspective transnationale a largement œuvré dans ce sens, mais cette ouverture a avant tout pour origine les méthodes mêmes des anthropologues, travaillant au plus près des gens sur leur terrain, les suivant dans les lieux où ils s'installent ou tentent de le faire, dans leurs multiples activités, dans leur quotidienneté. Leurs études rendent comptent à la fois de la labilité et de la profondeur des appartenances et des ancrages, démontrant régulièrement leur distance et leur critique à l'égard de propositions trop schématiques ou trop politiques, alors même que ces dernières persistent à se focaliser sur une migration africaine présentée comme potentiellement menaçante et à laquelle est donnée une visibilité artificielle (Lessault et Beauchemin, 2009).

Par ailleurs, ces études participent à la construction ou à la reconstruction, parfois très débattue, de la notion de diaspora dont les définitions les plus récentes saisissent le lieu d'origine de façon beaucoup plus complexe et mettent l'accent non plus uniquement sur la dimension spatiale du déplacement mais également sur sa dimension temporelle (Berthomière et Chivallon, 2006).

Sans doute, comme le remarque Jean-Pierre Warnier dans la préface du livre de Bouly de Lesdain, pour analyser un phénomène aussi complexe que la migration africaine, « aucune approche mono-disciplinaire ne fait l'affaire »; et il ne s'agit pas ici de dévaluer les autres disciplines, dont, d'ailleurs, les anthropologues se nourrissent ${ }^{69}$. Mais l'apport essentiel de l'anthropologie de la migration africaine en France est de montrer que son approche contribue autant à une meilleure connaissance des sociétés africaines ellesmêmes que des autres sociétés traversées.

69 Sans compter la porosité actuelle des sciences sociales, beaucoup plus importante qu'elle ne l'était lors des premières études de Barou. 


\section{Références bibliographiques ${ }^{70}$}

ADAMS Adrian (1977) Le long voyage des gens du Fleuve, Paris, François Maspero, 222 p.

ALBERS Irene (2006) 'Passion Dogon': Marcel Griaule und Michel Leiris. Die Geheimnisse des Dogon (und der Franzosen), in Tobias Wendl, Bettina von Lintig und Kerstin Pinther Eds, Black Paris. Kunst und Geschichte einer schwarzen Diaspora, Wuppertal, Peter Hammer Verlag, pp. 161-179.

AMIOTTE-SUCHET Laurent et FLOUX Pierre (2002) Voyage avec Pierre Centlivres, de l'Afghanistan aux communautés transnationales, ethnographiques.org [en ligne], $\mathrm{n}^{\circ} 1$, avril.

BAROU Jacques (1978) Travailleurs africains en France. Rôle des cultures d'origine, GrenobleParis, PUG/Publications orientalistes de France, $162 \mathrm{p}$.

BASTIDE Roger (1970) Mémoire collective et sociologie du bricolage, L'Année sociologique, pp. 65-108.

BAVA Sophie (2002) Chronique d'un pagne, in Michel Peraldi Dir., Cabas et containers, activités marchandes informelles et réseaux migrants transfrontaliers, Maisonneuve et Larose et MMMSH, pp. 315-327.

BERTHOMIÈRE William et CHIVALLON Christine Dir. (2006) Les diasporas dans le monde contemporain, Paris, Karthala-MSHA, 419 p.

BERTONCELLO Brigitte et BREDELOUP Sylvie (1999) Le Marseille des marins africains, Revue Européenne des Migrations Internationales, vol. 15, n 3, pp. 177-197.

BLANCHARD Pascal, DEROO Éric et MANCERON Yves (2001) Le Paris noir, Paris, Hazan, 234 p.

BOUDIMBOU Guy (1991) Habitat et modes de vie des immigrés africains en France, Paris, L'Harmattan, $269 \mathrm{p}$.

BOUILLY Emmanuelle (2008) Les enjeux féminins de la migration masculine : le collectif des femmes pour la lutte contre l'immigration clandestine de Thiaroye-sur-Mer, Politique africaine, $\mathrm{n}^{\circ} 109$, pp. 16-31.

BOULY de LESDAIN Sophie (1999) Femmes camerounaises en région parisienne : trajectoires migratoires et réseaux d'approvisionnement, Paris, L'Harmattan, $241 \mathrm{p}$.

BREDELOUP Sylvie (2008) L'aventurier, une figure de la migration africaine, Cahiers internationaux de sociologie, vol. $\mathrm{CXXV}^{\circ}{ }^{\circ}$ 2, pp. 281-306.

DAUM Christophe (1998) Les associations de Maliens en France : migrations, développement et citoyenneté, Paris, Karthala, 253 p.

DEROO Éric et CHAMPEAUX Antoine (2006) La Force noire. Gloires et infortunes d'une légende coloniale, Paris, Tallandier, $223 \mathrm{p}$.

DEWITTE Philippe (1985) Les mouvements nègres en France, 1919-1939, Paris, L'Harmattan, 415 p.

DIARRA Souleymane (1966) Problèmes d'adaptation des travailleurs africains noirs en France, Psychopathologie africaine, vol. II, $\mathrm{n}^{\circ}$ 1, pp. 107-126.

DIARRA Souleymane (1968) Les travailleurs africains noirs en France, BIFAN, t.XXX, série B, $\mathrm{n}^{\circ} 3$, pp. 884-1004.

DIOP Amadou Moustapha (1996) Société manjak et migration, Paris, s.e., 219 p.

DUBRESSON Alain (1975) Les travailleurs Soninké et Toucouleur dans l'Ouest parisien, Cahiers de l'ORSTOM, 12 (2), pp. 189-208.

FAINZANG Sylvie (1984) L'excision, ici et maintenant. Étude ethnologique, in Les mutilations $d u$ sexe des femmes, aujourd 'hui en France, ouvrage coll., Paris, Éditions Tierce, pp. 23-43.

FASSIN Didier (2000) Les politiques de l'ethnopsychiatrie. La psyché africaine, des colonies africaines aux banlieues parisiennes, L'Homme, 153, pp. 231-250.

FOGEL Frédérique (2007) Mémoires mortes ou vives. Transmission de la parenté chez les migrants, Ethnologie française, XXXVII, 3, pp. 509-516.

70 Nous ne reportons pas, dans cette bibliographie, les références des publications figurant en notes. 
FOUQUET Thomas (2007) Imaginaires migratoires et expériences multiples de l'altérité : une dialectique actuelle du proche et du lointain, Autrepart, $n^{\circ}$ 41, pp. 83-97.

GANDOULOU Justin-Daniel (1984) Entre Paris et Bacongo, Paris, Centre de création industrielle, Centre Georges Pompidou, 213 p.

JOURNET Odile et FAINZANG Sylvie (1989) La femme de mon mari. Étude ethnologique du mariage polygamique en Afrique et en France, Paris, L'Harmattan, 172 p.

KANE Francine et LERICOLLAIS André (1975) L'émigration en Pays soninké, Cahiers de l'ORSTOM, 12 (2), pp. 177-187.

KUCZYNSKI Liliane (2002) Les marabouts africains à Paris, Paris, CNRS Éditions, 439 p.

LESSAULT David et BEAUCHEMIN Cris (2009) Ni invasion ni exode. Regards statistiques sur les migrations d'Afrique subsaharienne, Revue Européenne des Migrations Internationales, vol. $25, \mathrm{n}^{\circ} 1$, pp. 163-194.

MANCHUELLE François (2004) Les diasporas des travailleurs soninké (1848-1960), migrants volontaires, Paris, Karthala, 348 p.

MCKAY Claude (1999) Banjo, Marseille, André Dimanche Éditeur, 330 p.

MICHEL Marc (2003) Les Africains et la Grande Guerre. L'appel à l'Afrique (1914-1918), Paris, Karthala, 302 p.

MILLS-AFFIF Édouard (2004) Filmer les immigrés : Les représentations audiovisuelles de l'immigration à la télévision française 1960-1986, Bruxelles, De Boeck, $299 \mathrm{p}$.

NICOLLET Albert (1992) Femmes d'Afrique noire en France. La vie partagée, Paris, L'Harmattan, 317 p.

PETIT Agathe (2002) La mort au loin. Les pratiques funéraires des migrants africains en France, thèse d'anthropologie sociale et ethnologie, EHESS, $359 \mathrm{p}$.

POIRET Christian (1996) Familles africaines : ethnicisation, ségrégation et communalisation, Paris, L'Harmattan, $448 \mathrm{p}$.

QUIMINAL Catherine (1991) Gens d'ici, gens d'ailleurs : migrations Soninké et transformations villageoises, Paris, Christian Bourgois, $222 \mathrm{p}$.

RAULIN Anne (1990) Problèmes éthiques d'une recherche en sciences sociales : l'excision et sa présence en France, Cahiers internationaux de sociologie, vol. LXXXVIII, pp. 157-171.

RAZY Élodie (2007) Les « sens contraires » de la migration. La circulation des jeunes filles d'origine soninké entre la France et le Mali, Journal des africanistes, 77 (2), pp. 19-43.

REZKALLAH Nadia et EPELBOIN Alain (1997) Chroniques du saturnisme infantile 1989-1994: enquête ethnologique auprès de familles parisiennes originaires du Sénégal et du Mali, Paris, L'Harmattan, $261 \mathrm{p}$.

SALZBRUNN Monika (2002) Hybridization of religion and political practices amongst West African muslim migrants in Paris, in Deborah Bryceson, Ulla Vuorela Eds., The transnational family. New european frontiers and global networks, Oxford, Berg, pp. 217-229.

SAMUEL Michel (1978) Le prolétariat africain noir en France, Paris, Éditions François Maspero, 262 p. (coll. Textes à l'appui).

SEMIN Jeanne (2007) L'argent, la famille et les amies. Ethnographie contemporaine des tontines africaines en contexte migratoire, in Françoise Lauwaert Dir., Après la catastrophe, Civilisations, vol. LVI (1-2), Bruxelles, ULB, pp. 183-199.

TALLON Brigitte et LEMOINE Maurice Dir. (1983) Black, Africains, Antillais... Cultures noires en France, Autrement, ${ }^{\circ}$ 49, 288 p.

TARRIUS Alain (1993) Territoires circulatoires et espaces urbains, Annales de la recherche urbaine, $\mathrm{n}^{\circ} 59-60$, pp. 51-60.

TIMERA Mahamet (1996) Les Soninké en France. D'une histoire à l'autre, Paris, Karthala, 244 p.

Vers des sociétés pluriculturelles : études comparatives et situation en France, 1987, Actes du Colloque international de l'AFA, Paris, Éditions de l'ORSTOM, 772 p.

WENDL Tobias, LINTIG Bettina von und PINTHER Kerstin Eds (2006) Black Paris. Kunst und Geschichte einer schwarzen Diaspora, Wuppertal, Peter Hammer Verlag, 432 p. 


\title{
Anthropologie et migrations africaines en France : une généalogie des recherches
}

\author{
Liliane KUCZYNSKI et Élodie RAZY
}

\begin{abstract}
À partir d'une revue de la littérature tant scientifique qu'associative ou encore étatique, cet article explore la production des connaissances en sciences sociales sur la migration africaine, longtemps restée un parent pauvre de l'anthropologie. Le point de vue critique sur l'histoire de l'africanisme, de même que sur les liens souvent ambigus entre monde de la recherche et sphère politique adopté ici permet d'explorer l'émergence des figures successives du migrant et de mieux comprendre la lente genèse de l'intérêt porté par les anthropologues à ce champ de recherche. Comment le «travailleur immigré » des années soixante est-il devenu un acteur à part entière ? Quelle place ont prise les femmes dans le traitement de la question? Pourquoi certaines thématiques ont-elles été privilégiées plutôt que d'autres à certaines époques ? Quels sont les écrits et les personnalités scientifiques qui ont pesé dans le processus décrit? Telles sont quelques unes des questions auxquelles des éléments de réponse sont apportés dans cet article.
\end{abstract}

\section{Anthropology and African Migrations in France: A Genealogy of Researches}

\section{Liliane KUCZYNSKI and Élodie RAZY}

Based on a review of scientific, associative and state productions, this article explores the development of knowledge in social sciences concerning African migrations as related to France. This field was underestimated for a long time by French anthropologists. With a critical point of view on africanism history and on the often ambiguous links between the researchfield and the political sphere, the authors explore the successive emerging figures of the migrant and analyze the slowly growing interest of anthropologists in this issue. How has the "immigrant worker" of the sixties become a fully committed protagonist? What was women's place in this process? What where the themes with greater importance and at what period? Which writings and which scientific authors have weighed in this process? These are some of the questions that this article will try to answer.

\section{Antropología y migraciones africanas en Francia: genealogía de las investigaciones}

\author{
Liliane KUCZYNSKI y Élodie RAZY
}

Apoyándose sobre una revista de las publicaciones tanto científicas como asociativas o estatales este artículo explora la producción de saberes sobre la migración africana, que fue durante años poco estudiada por los antropólogos. Una mirada crítica de la historia del africanismo y también de los lazos ambiguos entre el mundo político y el de la investigación permite explorar la emergencia de las figuras sucesivas del migrante y entender así el lento crecimiento del interés que los antropólogos dedicaron a este campo de investigación. ¿Como el «trabajador inmigrante» de los años sesenta se convirtió en actor social de plena participación? ¿Qué espacio han ocupado las mujeres en los estudios? ¿Por qué se privilegiaron ciertas temáticas y no otras en ciertos momentos? ¿Cuáles son los textos y las personalidades científicas que han intervinieron en el proceso descrito? Estas son algunas de las preguntas a los cuales este artículo trae elementos de respuesta. 